\title{
SELEÇÃO DE DOCENTES PARA CURSOS DE GRADUAÇÃO E PÓS- GRADUAÇÃO EM INSTITUIÇÃO DE ENSINO SUPERIOR
}

\author{
Ana Lucia Pegetti \\ Instituto Tecnológico de Aeronáutica \\ Praça Marechal Eduardo Gomes, 50 - Vila das Acácias, SJC - SP, 12228-900 \\ apegetti@ita.br \\ Glayse Ferreira Perroni da Silva \\ Instituto Tecnológico de Aeronáutica \\ Praça Marechal Eduardo Gomes, 50 - Vila das Acácias, SJC - SP, 12228-900 \\ glayse@ita.br \\ Mischel Carmen Neyra Belderrain \\ Instituto Tecnológico de Aeronáutica \\ Praça Marechal Eduardo Gomes, 50 - Vila das Acácias, SJC - SP, 12228-900 \\ carmen@ita.br
}

\section{RESUMO}

A fim de aumentar a eficiência na gestão de seus recursos institucionais, as instituições de ensino superior privado do Brasil vêm adotando métodos de gestão alinhadas com as melhores práticas de mercado. Assim sendo, a contratação de profissionais competentes e alinhados aos valores institucionais é de suma importância para manter a empresa competitiva e evitar os impactos negativos que contratações erradas podem trazer. Desta forma, este trabalho tem como objetivo apresentar uma proposta para seleção de docentes que atendam às expectativas organizacionais, através da aplicação do método de estruturação de problemas Value Focused Thinking (VFT) para definição dos valores e objetivos dos decisores; e o método Multi-attribute value theory (MAVT) para seleção da alternativa mais consistente com os julgamentos de valor dos mesmos.

Palavra-chave: Seleção de docentes; Decisão multicritério; VFT; MAVT.

\begin{abstract}
In order to increase the efficiency in the management of their institutional resources, Brazilian private higher education institutions have been adopting management methods aligned with the best market practices. Therefore, hiring competent professionals aligned with institutional values is of paramount importance to keep the company competitive and avoid the negative impacts that wrong hiring can bring. Thus, this paper aims to present a proposal for the selection of teachers who meet organizational expectations through the application of the Value Focused Thinking (VFT) problem structuring method to define the values and objectives of decision makers; and the Multi-attribute value theory (MAVT) method for selecting the alternative most consistent with the value judgments of them.
\end{abstract}

Keywords: Teacher selection; Multicriteria decision; VFT; MAVT. 


\section{Como Citar:}

PEGETTI, Ana Lucia; DA SILVA, Glayse Ferreira Perroni; BELDERRAIN, Mischel Carmen Neyra. Seleção de Docentes para Cursos de Graduação e Pós-graduação em Instituição de Ensino Superior. In: SIMPÓSIO DE PESQUISA OPERACIONAL E LOGÍSTICA DA MARINHA, 19., 2019, Rio de Janeiro, RJ. Anais [...]. Rio de Janeiro: Centro de Análises de Sistemas Navais, 2019.

\section{INTRODUÇÃO}

Para garantir sua permanência no mercado de trabalho, as empresas têm, cada vez mais, investindo na melhoria de seus processos institucionais. Neste contexto, o processo de seleção de pessoas é uma etapa importante para qualquer empresa. Nas últimas décadas, as instituições de ensino superior privado do Brasil vêm sofrendo grandes desafios na tentativa de institucionalizar práticas administrativas aplicadas no mercado empresarial com o objetivo principal de aperfeiçoar seus processos de trabalho e reduzir riscos e custos operacionais, aumentando assim sua produtividade e qualidade dos serviços prestados. Estas iniciativas visam manter as instituições autossustentáveis e competitivas em um mercado agressivo em constante expansão e estruturar melhor essa etapa de forma a garantir uma contratação mais assertiva e que agregue maior valor aos resultados organizacionais e atendimento a comunidade.

Neste contexto, contratar novos funcionários exige um planejamento estratégico da empresa para dar certo. Realizar um processo seletivo assertivo é vital para evitar os impactos negativos que contratações erradas podem trazer. A seleção de pessoal constitui-se em um processo complexo, na medida em que envolve critérios subjetivos, além dos objetivos presentes nos regulamentos e editais. Em estudo realizado acerca da contratação de docentes em instituições de ensino federais, [1] afirma que a avaliação da competência docente para atuação no ensino superior está, em grande parte, restrita à atuação no ensino e as dimensões pesquisa e extensão avaliadas de forma pontual na análise do currículo dos candidatos. Atualmente, a questão da contratação docente é ainda mais preocupante, já que os profissionais tendem a permanecer pouco tempo nas empresas e a falta de um processo estruturado na seleção de talentos pode resultar na contratação de profissionais totalmente inadequados para a função. Para [2] talento é o conjunto de habilidades de uma pessoa - seus dons, conhecimento, experiência, inteligência, discernimento, atitude, caráter e impulsos inatos, o que inclui sua capacidade de aprender.

Como o recurso mais significativo e caro nas escolas, os professores são fundamentais para os esforços de melhoria e melhorar a eficiência e equidade da educação depende, em grande parte, de garantir que as pessoas competentes sejam contratadas e que seu ensino seja de alta qualidade. Esses problemas relacionados à contratação podem vir desde a falta de experiência necessária para o cargo, falhas nas habilidades técnicas ou até mesmo desalinhamento da personalidade do trabalhador com a cultura organizacional da empresa, o que resulta cedo ou tarde em uma demissão e um novo processo seletivo para o mesmo cargo.

Uma empresa com alta rotatividade de funcionários tem mais gastos com a administração de pessoas. Toda vez que um profissional pede as contas ou é demitido, há os custos de rescisão e direitos que a organização deve acertar, ocorrendo toda uma adaptação da equipe que inevitavelmente tem uma queda em seus índices de produção, além dos gastos 
com o processo seletivo e adaptação do novo funcionário e a problemática da fácil disseminação da reputação da empresa através das redes sociais.

Neste contexto, um fator que contribui para uma melhor seleção dos docentes é a definição de competências e habilidades, devendo estas, estarem alinhadas aos valores institucionais. Quanto mais alinhado estiver o processo de seleção com a instituição de ensino, melhor será o resultado da captação de profissionais para compor a sua equipe [3].

Este trabalho objetiva desenvolver junto aos decisores da IES, representantes, respectivamente, do Departamento de Recursos Humanos, do Coordenador do Programa de Pós-Graduação em Educação e do Coordenador da Graduação dos cursos de Licenciatura, um processo que represente o processo decisório real existente na seleção de docentes que além do atendimento dos critérios objetivos descritos no edital, atendam aos valores organizacionais. O trabalho está estruturado em cinco seções, além desta introdução: 2 . Referencial Teórico, 3. Desenvolvimento do Modelo, 4. Apresentação dos Resultados e 5. Considerações Finais. A abordagem metodológica para o estudo é uma análise exploratóriodescritiva, que, segundo [4], representa o tipo ideal de abordagem para desenvolver hipóteses iniciais de trabalho sobre o assunto analisado. As conclusões do trabalho seguem a lógica indutiva, buscando generalizar as conclusões obtidas.

\section{REFERENCIAL TEÓRICO}

As subseções a seguir apresentam o referencial teórico sobre o qual se apoia o desenvolvimento do presente trabalho.

\subsection{PROCESSO DE SELEÇÃO DE DOCENTES}

O processo seletivo para a contratação dos docentes que atuarão nos cursos de PósGraduação Stricto Sensu e Graduação da IES, é constituído de quatro etapas, sendo a primeira etapa eliminatória e caracterizada pelo atendimento aos pré-requisitos do edital. Na segunda etapa, os decisores realizam uma análise curricular baseada em competências declaradas no edital e que melhor atendam às exigências do cargo e da universidade. Na terceira etapa, é agendada uma aula teste, com duração de até trinta minutos, onde se busca avaliar os conhecimentos relacionados à sua área de formação, didática, processo de ensinoaprendizagem, verificando a capacidade de expressão de ideias e o grau de atualização de seus conhecimentos na área de atuação. Nesta etapa, o nível de raciocínio, comunicabilidade, a qualidade da argumentação, e o comportamento frente a comentários adversos são avaliados. A última etapa do processo seletivo antes dos trâmites burocráticos junto ao Departamento de Recursos Humanos é a realização de uma entrevista conjunta semiestruturada com os coordenadores de área onde se busca avaliar o candidato quanto às suas características pessoais e seus valores, de forma a avaliar se estes estão alinhados aos valores institucionais. A duração média dessa etapa é de uma hora, de forma que as respostas são analisadas e anotadas em ficha individual, com base em critérios previamente definidos. Ela tem como objetivos conhecer melhor o candidato e seu contexto de vida, esclarecer dúvidas surgidas durante as várias etapas da seleção, obter respostas para as hipóteses levantadas acerca do candidato durante o processo, explorar a sua disposição para a aprendizagem, pensando na formação continuada de professores, e fornecer feedback sobre seu desempenho ao longo do processo seletivo. São ainda contextualizadas algumas situações de trabalho para que o candidato relate como agiria frente a elas, visando explorar seu posicionamento perante um conjunto de questões éticas no ambiente de trabalho. 


\subsection{PROCESSO DE APOIO MULTICRITÉRIO À DECISÃO}

Segundo [5], a escolha por fazer uma coisa ao invés de outra ou fazê-la de determinada forma, caracteriza a tomada de uma decisão que pode ser feita por uma ou mais decisores que apresentem interesses relevantes e diversificados em função dos valores individuais. A decisão pode ser encarada como um processo contínuo, com muitas confrontações e interações entre os decisores, de forma que além dos aspectos objetivos, sendo impossível desconsiderar os aspectos subjetivos do decisor, como seus valores, objetivos, crenças, preconceitos, cultura e intuição. Desta forma, neste artigo, será utilizada uma abordagem construtivista para a determinação dos critérios norteadores para a seleção de docentes que irão atuar junto aos cursos de graduação e pós-graduação.

O processo de decisão para a seleção de docentes é considerado um processo de tomada de decisão complexo, pois se caracteriza por apresentar interesses heterogêneos e conflitantes das partes interessadas, vários objetivos a serem alcançados, longos processos de planejamento e implementação e resultados incertos. Na maioria das vezes, o processo de tomada de decisão, envolve a escolha da melhor decisão levando em conta múltiplos critérios, fatores ou objetivos. Em um ambiente organizacional, é comum o decisor envolver-se em situações em um ambiente instável, com muitas mudanças, incertezas, ambiguidades e imprecisão. É impossível determinar uma solução ótima que satisfaça plenamente a todos os objetivos em problemas com múltiplos objetivos. Para estes casos, é necessário encontrar uma solução de consenso onde é necessário determinar um nível de conciliação dos objetivos múltiplos, sendo a melhor decisão aquela que minimiza perdas, maximiza ganhos e agrega valor do ponto de vista do decisor. Nesse sentido, várias técnicas têm sido utilizadas até o momento envolvendo a Análise de Decisão Multicritério (MCDA). Inicialmente, o foco estava em fornecer ferramentas de otimização e modelagem. Atualmente, a ênfase é colocada em ferramentas não apenas dirigidas para auxiliar os processos de tomada de decisão, mas também para fins de negociação diretamente entre as partes interessadas.

As metodologias voltadas ao apoio à decisão adotam o construtivismo como paradigma científico, ao contrário das metodologias voltadas à tomada de decisão, que seguem o paradigma racionalista. Assim as metodologias multicritério em apoio à decisão (MCDA) enquadram-se no primeiro caso, O MCDA é um campo de pesquisa operacional e um método quantitativo para avaliar critérios múltiplos e geralmente conflitantes ao tomar uma decisão [6]. A MCDA assume a formulação de todos os critérios relacionados ao processo de decisão em termos quantitativos e, em geral, várias abordagens têm sido propostas para a MCDA, entre elas, está o Método de Avaliação de Sintetização Única, no qual todos os critérios são agregados em um único valor como Multi-Attribute Value Theory (MAVT) ou Multi-Attribute Utility Theory (MAUT).

$\mathrm{Na}$ análise de [7] o processo de apoio multicritério à decisão considera três fases: Estruturação da situação problemática, Estruturação do modelo multicritério e Avaliação de Alternativas como mostrado na Figura 1. 


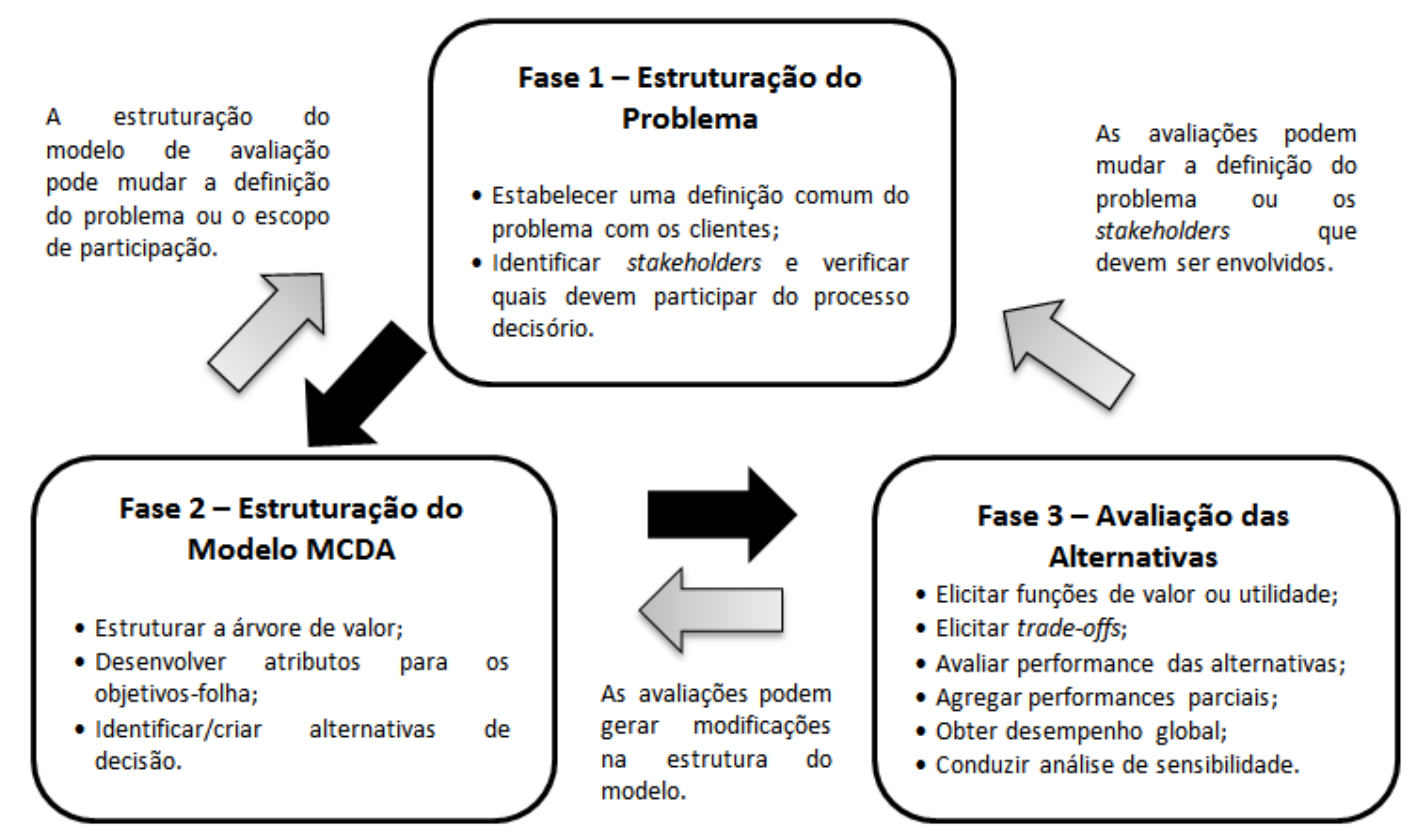

Figura 1: Um framework para estruturar modelos MCDA Fonte: Franco e Montibeller (2010)

$\mathrm{Na}$ proposta deste trabalho, a estruturação do problema será realizada utilizando a abordagem Value-Focused Thinking (VFT) para a definição da árvore de valor. A estruturação do modelo multicritério e avaliação de alternativas serão realizadas pelo método MAVT.

\subsection{VALUE FOCUSED THINKING (VFT)}

É comum os métodos de tomada de decisão primeiramente estabelecerem alternativas e depois introduzirem objetivos para a avaliação destas [8]. Pensando em qual razão leva um decisor a tomar uma decisão, percebemos que este se dá porque ele precisa alcançar algo de valor e para isso, é preciso que o foco do processo decisório seja dado a como tais alternativas são ou podem ser estabelecidas, e a melhor maneira de conseguir isso é pensando-se em valores e objetivos. O foco do VFT está nos valores do decisor. Um objetivo é uma representação de um valor em termos de um verbo e um objeto, como "minimizar custo" ou "reduzir a quantidade de refugo". Assim, os valores são explicitados especificando os objetivos do decisor. Neste contexto, a abordagem VFT enfatiza que a identificação dos objetivos do decisor é mais importante do que comparar alternativas conhecidas para resolver o problema. A identificação de valores pode ajudar na identificação de novas alternativas. A relevância da estruturação do problema decisório se dá porque força o decisor a primeiro pensar sobre a decisão a ser tomada e depois, a definir os objetivos fundamentais e objetivos meio e seus relacionamentos.

Estruturar objetivos envolve o estabelecimento de uma hierarquia de valores a partir de objetivos fundamentais [10] (incluir todos os aspectos fundamentais das consequências das alternativas de decisão); não redundante (evitar dupla contagem de possíveis consequências); conciso (reduzir o número de objetivos necessários para a análise de uma decisão); específico (os objetivos devem ser claramente especificados para que os graus para os quais cada 
objetivo possa ser alcançado possam ser definidos); e compreensível (facilitar a geração e comunicação de insights para orientar o processo de tomada de decisão). Geralmente, os valores são elicitados pelos facilitadores através da realização de entrevistas e workshops com os decisores e outras partes interessadas. O VFT deve ser implementado em cinco etapas nos problemas de decisão: (1) Reconhecer o problema de decisão; (2) Especificar valores; (3) Criar alternativas; (4) Avaliar alternativas; e (5) Selecionar uma alternativa [8].

\subsection{TEORIA DO VALOR DE MÚLTIPLOS ATRIBUTOS (MAVT)}

A Teoria do Valor de Múltiplos Atributos (MAVT) pode ser usada para abordar problemas que envolvem um conjunto finito e discreto de políticas alternativas que devem ser avaliadas com base em objetivos conflitantes. Para qualquer objetivo, um ou mais atributos ou critérios diferentes são usados para medir o desempenho em relação a esse objetivo. Esses aspectos, os impactos de todas as opções alternativas para todos os atributos, são apresentados em uma tabela de avaliação. Esses atributos geralmente são medidos em diferentes escalas de medida.

A intenção do MAVT é construir um meio de associar um número real a cada alternativa, a fim de produzir uma ordem de preferência nas alternativas consistentes com os julgamentos de valor do tomador de decisão. Para fazer isso, o MAVT assume que em cada problema de decisão existe uma função de valor real $U$ que representa as preferências do tomador de decisão. Essa função U é usada para transformar os atributos de cada política alternativa em um único valor. A alternativa com o melhor valor é apontada como a melhor.

O processo para se implementar o MAVT consiste nos seguintes passos:

- Definição de alternativas: identificar as alternativas que devem ser comparadas entre si.

- Seleção e definição de critérios: identificar os efeitos ou indicadores relevantes para a decisão.

- Avaliação das pontuações para cada alternativa em termos de cada critério: atribuir valores a cada efeito ou indicador para todas as alternativas.

- Classificação da alternativa: uma pontuação total é calculada para cada alternativa, aplicando uma função de valor U às pontuações de todos os critérios.

O MAVT baseia-se no pressuposto de que em cada problema de decisão existe uma função de valor real $U$ que representa as preferências do tomador de decisão. Esta função agrega para cada alternativa aj $(\mathrm{j}=1 . . \mathrm{M})$ os critérios ci $(\mathrm{i}=1 . . \mathrm{N})$ que estão sendo considerados pelo tomador de decisão. Os conceitos teóricos do MAVT foram descritos por [8].

\section{DESENVOLVIMENTO DO MODELO}

Neste trabalho, a definição dos decisores deu-se através da identificação dos responsáveis dos pelas áreas de negócio afetadas pela contratação dos docentes e às quais estes ficarão subordinados. Para o reconhecimento do problema, foram conduzidas reuniões de brainstorming com os responsáveis, e em um processo interativo, investigaram-se os conceitos relacionados ao problema a fim de explorar o entendimento dos decisores sobre o problema a ser resolvido.

Em um segundo momento, para a identificação dos valores dos decisores, foi perguntado o que se desejavam alcançar na situação do problema de forma que suas respostas fornecessem uma lista de potenciais objetivos. 
Os valores fornecem a base para o interesse em qualquer situação de decisão pois são explicitados pela identificação de objetivos. Existem várias técnicas para estimular identificar objetivos envolvidos na estruturação de problema, sendo que se optou pela criação de uma lista dos objetivos desejados. Após listar os objetivos, estabeleceu-se as relações entre eles e examinou-se a razão de terem sido escolhidos. De acordo com [8], os objetivos podem ser definidos em:

- Objetivos Fundamentais: representam os fins que os decisores almejam em um contexto de decisão;

- Objetivos Meios: representam formas/maneiras para se alcançar outros objetivos;

- Objetivos Estratégicos: são objetivos fundamentais que direcionam a tomada de todas as decisões organizacionais e são utilizados para se tomar decisões no nível estratégico de uma organização.

Definidos os objetivos fundamentais, definiram-se os objetivos meios que são aqueles necessários para que se possam cumprir os objetivos fundamentais. Para separar os objetivos em fundamentais e meios, utilizou-se o teste Why Is That Important (WITI), perguntando para cada objetivo "Por que isso é importante?". Se a resposta é que esse objetivo é uma das razões essenciais de interesse na situação, aquele é um objetivo fundamental. Já se a resposta for que aquele objetivo é importante para alcançar outro objetivo, aquele então será um objetivo meio [9]. Desta forma, constrói-se a hierarquia entre os objetivos fundamentais e uma rede de objetivos meios e fins com o propósito de orientar o decisor nas possíveis alternativas a serem tomadas para alcançar o resultado.

O próximo passo foi estabelecer os mecanismos de medida através da definição de atributos adequados de forma a construir a modelo de valor capaz de ajudar um decisor a priorizar objetivos e mensurá-los. A identificação das alternativas se dá diretamente pelos docentes candidatos que fazem sua inscrição no processo seletivo descrito no edital de contratação que deve atender aos critérios obrigatórios para classificação no processo seletivo nele descritos.

\subsection{APLICAÇÃO DO VFT E IDENTIFICAÇÃO DA HIERARQUIA DOS OBJETIVOS FUN- DAMENTAIS}

Para este trabalho, o processo de aplicação do VFT foi iniciado com a tarefa de estruturar os valores e identificar os objetivos, obtidos através da aplicação de um questionário, semiestruturado para os coordenadores de cursos a fim de se criar um melhor entendimento acerca de seus valores sobre o problema, a partir das questões do Quadro 1:

Quadro 1: Questões para estruturar valores

\begin{tabular}{|c|c|}
\hline Número & Questão \\
\hline 1 & $\begin{array}{l}\text { Qual a importância da contratação de um docente que atenda a cursos de níveis } \\
\text { diferentes? }\end{array}$ \\
\hline 2 & Quais as dificuldades identificadas neste tipo de contratação? \\
\hline 3 & Poderia citar algumas vantagens e desvantagens sobre este tipo de contratação? \\
\hline 4 & Poderia citar dificuldades em relação a este processo de contratação? \\
\hline 5 & $\begin{array}{l}\text { Consegue identificar algum impacto relevante sobre este processo para a } \\
\text { instituição? }\end{array}$ \\
\hline 6 & $\begin{array}{l}\text { Existe alguma restrição para a contratação de docentes do ponto de vista } \\
\text { institucional? }\end{array}$ \\
\hline
\end{tabular}




\begin{tabular}{|c|c|}
\hline Número & Questão \\
\hline 7 & Que características interpessoais julga importante o docente ter? \\
\hline
\end{tabular}

A partir das informações obtidas nas entrevistas, foi possível identificar os valores dos decisores e transformá-los em objetivos, identificando-se o objetivo estratégico, os objetivos fundamentais e a rede de objetivos meios e fins. A hierarquia de objetivos fundamentais pode ser observada no Quadro 2:

Quadro 2: Hierarquia dos objetivos fundamentais

\begin{tabular}{|c|c|}
\hline 01 & $\begin{array}{l}\text { Maximizar aderência do docente aos valores institucionais } \\
\text { 1.1 Maximizar a participação ativa na comunidade cristã } \\
\text { 1.1.1 Nível de participação } \\
\text { 1.2 Maximizar o envolvimento com projetos comunitários ou voluntários } \\
\text { 1.2.1 Nível de envolvimento } \\
\text { 1.3 Maximizar a formação tradicional familiar } \\
\text { 1.3.1 Nível de aderência ao quesito }\end{array}$ \\
\hline $\mathrm{O} 2$ & $\begin{array}{l}\text { Maximizar a pontuação da IES junto a órgãos reguladores de educação } \\
\text { 2.1 Maximizar o nível de qualificação docente } \\
\text { 2.1.1 Nível de formação docente } \\
\text { 2.2 Maximizar a quantidade de produção cientifica } \\
\text { 2.2.1 Nível de orientações realizadas por nível de ensino } \\
\text { 2.2.2 Nível de publicações realizadas em periódicos científicos } \\
\text { 2.2.3 Nível de participações em congressos e seminários } \\
\text { 2.3 Maximizar o tempo de dedicação docente na instituição } \\
\text { 2.3.1 Quantidade de horas semanais de dedicação docente }\end{array}$ \\
\hline $\mathbf{O 3}$ & $\begin{array}{l}\text { Maximizar a percepção da qualidade do curso pelo aluno } \\
\text { 3.1 Maximizar a experiência acadêmica do docente } \\
\text { 3.1.1 Quantidade de anos de trabalho docente } \\
\text { 3.1.2 Qualidade das instituições de ensino em que trabalhou } \\
\text { 3.2 Maximizar a experiência profissional do docente } \\
\text { 3.2.1 Quantidade de anos de trabalho profissional } \\
\text { 3.2.2 Quantidade certificações específicas na área de atuação }\end{array}$ \\
\hline 04 & $\begin{array}{l}\text { Maximizar as competências pedagógicas observadas no docente } \\
\text { 4.1 Maximizar a capacidade de planejamento de aula } \\
\text { 4.1.1 Didática } \\
\text { 4.1.2 Capacidade de argumentação } \\
\text { 4.1.3 Capacidade de trabalho em ambiente adverso } \\
\text { 4.2 Maximizar o conhecimento docente na área de educação } \\
\text { 4.2.1 Conhecimento em práticas pedagógicas } \\
\text { 4.2.2 Conhecimento em legislação educacional } \\
\text { 4.2.3 Conhecimento na área da disciplina }\end{array}$ \\
\hline
\end{tabular}

\subsection{ESTRUTURAÇÃO DA ÁRVORE DE VALOR (ATRIBUTOS RELEVANTES PARA O PROBLEMA DE DECISÃO)}

O principal motivo de ter-se identificado, anteriormente, os valores e gerado os objetivos foi a definição dos atributos e a construção da árvore de valor para este problema de decisão. A árvore de valor é apresentada na Figura 2. 


\subsection{DEFINIÇÃO DAS MÉTRICAS DOS ATRIBUTOS}

Para medir os objetivos fundamentais, após a definição dos atributos é necessário estabelecer as métricas para estes atributos. Estas estão representadas no Quadro 3.

Quadro 3: Atributos e métricas

\begin{tabular}{|c|c|c|c|c|c|}
\hline Objetivo & Atributo & $\begin{array}{l}\text { Tipo de } \\
\text { Atributo }\end{array}$ & Descrição & \multicolumn{2}{|c|}{ Escala } \\
\hline $\begin{array}{c}\text { Maximizar a } \\
\text { participação ativa } \\
\text { na comunidade } \\
\text { cristã }\end{array}$ & $\begin{array}{c}\text { Nível de } \\
\text { participação }\end{array}$ & Construído & $\begin{array}{c}\text { Indica qual o grau de } \\
\text { participação do candidato } \\
\text { na comunidade religiosa } \\
\text { local }\end{array}$ & Ordinal & $\begin{array}{c}\text { Adimen } \\
\text { sional }\end{array}$ \\
\hline $\begin{array}{c}\text { Maximizar o } \\
\text { envolvimento } \\
\text { com projetos } \\
\text { comunitários ou } \\
\text { voluntários }\end{array}$ & $\begin{array}{c}\text { Nível de } \\
\text { envolvimento }\end{array}$ & Construído & $\begin{array}{c}\text { Indica o grau de } \\
\text { envolvimento do candidato } \\
\text { com projetos comunitários } \\
\text { ou trabalho voluntário }\end{array}$ & Ordinal & $\begin{array}{c}\text { Adimen } \\
\text { sional }\end{array}$ \\
\hline $\begin{array}{l}\text { Maximizar a } \\
\text { formação } \\
\text { tradicional } \\
\text { familiar }\end{array}$ & $\begin{array}{l}\text { Nível de } \\
\text { aderência }\end{array}$ & Construído & $\begin{array}{l}\text { Indica se o candidato tem } \\
\text { família constituída } \\
\text { tradicionalmente }\end{array}$ & Ordinal & $\begin{array}{c}\text { Adimen } \\
\text { sional }\end{array}$ \\
\hline $\begin{array}{l}\text { Maximizar o } \\
\text { nível de } \\
\text { qualificação } \\
\text { docente }\end{array}$ & $\begin{array}{l}\text { Nível de } \\
\text { formação }\end{array}$ & Construído & $\begin{array}{c}\text { Indica o maior nível de } \\
\text { formação acadêmica do } \\
\text { candidato. Este atributo } \\
\text { leva em conta o maior nível } \\
\text { acadêmico alcançado em } \\
\text { IES reconhecidas por sua } \\
\text { excelência. }\end{array}$ & Ordinal & $\begin{array}{c}\text { Adimen } \\
\text { sional }\end{array}$ \\
\hline \multirow{3}{*}{$\begin{array}{l}\text { Maximizar a } \\
\text { quantidade de } \\
\text { produção } \\
\text { cientifica }\end{array}$} & $\begin{array}{l}\text { Nível de } \\
\text { orientações }\end{array}$ & Construído & $\begin{array}{l}\text { Quantidade de orientações } \\
\text { por nível de estudo. Este } \\
\text { atributo avalia com maior } \\
\text { nota quantidades de } \\
\text { orientações em Doutorado, } \\
\text { Mestrado e Graduação, } \\
\text { respectivamente. }\end{array}$ & Ordinal & $\begin{array}{c}\text { Adimen } \\
\text { sional }\end{array}$ \\
\hline & $\begin{array}{l}\text { Nível de } \\
\text { publicações }\end{array}$ & Construído & $\begin{array}{l}\text { Quantidade de publicações } \\
\text { em periódicos. Este atributo } \\
\text { considera, somente, } \\
\text { publicações em periódicos } \\
\text { com Qualis A1, A2, B2 e } \\
\text { B1; avaliando com maior } \\
\text { nota publicações realizadas } \\
\text { nesta ordem. }\end{array}$ & Ordinal & $\begin{array}{c}\text { Adimen } \\
\text { sional }\end{array}$ \\
\hline & $\begin{array}{c}\text { Nível de } \\
\text { participações } \\
\text { em congressos }\end{array}$ & Construído & $\begin{array}{c}\text { Quantidade de } \\
\text { participações em } \\
\text { congressos e seminários } \\
\text { nacionais e internacionais, } \\
\text { reconhecidos pela sua } \\
\text { excelência, tendo maior } \\
\text { pontuação os congressos } \\
\text { internacionais. }\end{array}$ & Ordinal & $\begin{array}{c}\text { Adimen } \\
\text { sional }\end{array}$ \\
\hline
\end{tabular}




\begin{tabular}{|c|c|c|c|c|c|}
\hline Objetivo & Atributo & $\begin{array}{l}\text { Tipo de } \\
\text { Atributo }\end{array}$ & Descrição & \multicolumn{2}{|c|}{ Escala } \\
\hline $\begin{array}{l}\text { Maximizar } \\
\text { dedicação } \\
\text { docente na } \\
\text { instituição }\end{array}$ & $\begin{array}{l}\text { Quantidade de } \\
\text { horas de } \\
\text { dedicação } \\
\text { semanal }\end{array}$ & Construído & $\begin{array}{l}\text { Disponibilidade semanal do } \\
\text { candidato à IES. Quanto } \\
\text { maior a quantidade de } \\
\text { tempo para a IES, melhor } \\
\text { sua avaliação. }\end{array}$ & Ordinal & $\begin{array}{c}\text { Adimen } \\
\text { sional }\end{array}$ \\
\hline \multirow{2}{*}{$\begin{array}{l}\text { Maximizar a } \\
\text { experiência } \\
\text { acadêmica }\end{array}$} & $\begin{array}{l}\text { Quantidade de } \\
\text { anos de } \\
\text { trabalho } \\
\text { docente }\end{array}$ & Construído & $\begin{array}{l}\text { Tempo de trabalho docente. } \\
\text { Quanto maior a quantidade } \\
\text { de anos trabalhados como } \\
\text { docente, melhor sua } \\
\text { avaliação. }\end{array}$ & Ordinal & $\begin{array}{c}\text { Adimen } \\
\text { sional }\end{array}$ \\
\hline & $\begin{array}{c}\text { Nível de } \\
\text { qualidade das } \\
\text { instituições de } \\
\text { ensino em que } \\
\text { trabalhou }\end{array}$ & Construído & $\begin{array}{c}\text { Nível de excelência das IES } \\
\text { em que trabalhou. }\end{array}$ & Ordinal & $\begin{array}{l}\text { Adimen } \\
\text { sional }\end{array}$ \\
\hline \multirow[t]{2}{*}{$\begin{array}{l}\text { Maximizar a } \\
\text { experiência } \\
\text { profissional }\end{array}$} & $\begin{array}{l}\text { Quantidade de } \\
\text { anos de } \\
\text { experiência } \\
\text { profissional }\end{array}$ & Construído & $\begin{array}{c}\text { Tempo de experiência } \\
\text { profissional. } \\
\text { Quanto maior a quantidade } \\
\text { de anos trabalhados em } \\
\text { áreas relacionadas a } \\
\text { formação, melhor sua } \\
\text { avaliação. } \\
\end{array}$ & Ordinal & $\begin{array}{c}\text { Adimen } \\
\text { sional }\end{array}$ \\
\hline & $\begin{array}{l}\text { Quantidade de } \\
\text { certificações } \\
\text { profissionais }\end{array}$ & Construído & $\begin{array}{l}\text { Quantidade de certificações } \\
\text { específicas da área de } \\
\text { atuação. Quanto maior a } \\
\text { quantidade de certificados, } \\
\text { melhor sua avaliação. } \\
\end{array}$ & Ordinal & $\begin{array}{c}\text { Adimen } \\
\text { sional }\end{array}$ \\
\hline \multirow{3}{*}{$\begin{array}{c}\text { Maximizar a } \\
\text { capacidade de } \\
\text { planejamento de } \\
\text { aula }\end{array}$} & Didática & Construído & $\begin{array}{l}\text { Capacidade de aplicação } \\
\text { preceitos científicos que } \\
\text { orientam a atividade } \\
\text { educativa de modo a torná- } \\
\text { la mais eficiente. Este } \\
\text { atributo será avaliado em } \\
\text { três níveis. } \\
\end{array}$ & Ordinal & $\begin{array}{c}\text { Adimen } \\
\text { sional }\end{array}$ \\
\hline & $\begin{array}{l}\text { Capacidade de } \\
\text { argumentação }\end{array}$ & Construído & $\begin{array}{l}\text { Capacidade do candidato de } \\
\text { articular ideias, demonstrar } \\
\text { competências de raciocínio } \\
\text { crítico comunicabilidade. }\end{array}$ & Ordinal & $\begin{array}{c}\text { Adimen } \\
\text { sional }\end{array}$ \\
\hline & $\begin{array}{l}\text { Capacidade de } \\
\text { trabalho em } \\
\text { ambiente } \\
\text { adverso }\end{array}$ & Construído & $\begin{array}{c}\text { Capacidade } \\
\text { comportamental do } \\
\text { candidato de manter-se } \\
\text { equilibrado ao ser } \\
\text { confrontado com ideias } \\
\text { adversas as suas. Será } \\
\text { avaliado seu grau de } \\
\text { equilíbrio diante de } \\
\text { adversidades. }\end{array}$ & Ordinal & $\begin{array}{c}\text { Adimen } \\
\text { sional }\end{array}$ \\
\hline
\end{tabular}




\begin{tabular}{|c|c|c|c|c|c|}
\hline Objetivo & Atributo & $\begin{array}{c}\text { Tipo de } \\
\text { Atributo }\end{array}$ & Descrição & \multicolumn{2}{|c|}{ Escala } \\
\hline \multirow{3}{*}{$\begin{array}{l}\text { Maximizar o } \\
\text { conhecimento } \\
\text { docente na área } \\
\text { de educação }\end{array}$} & $\begin{array}{l}\text { Conhecimento } \\
\text { em práticas } \\
\text { pedagógicas }\end{array}$ & Construído & $\begin{array}{l}\text { Capacidade de aplicação de } \\
\text { práticas pedagógicas } \\
\text { adequadas considerando o } \\
\text { contexto social específico. }\end{array}$ & Ordinal & $\begin{array}{c}\text { Adimen } \\
\text { sional }\end{array}$ \\
\hline & $\begin{array}{c}\text { Conhecimento } \\
\text { em legislação } \\
\text { educacional }\end{array}$ & Construído & $\begin{array}{c}\text { Conhecimento da } \\
\text { legislação educacional } \\
\text { básica em vigor. O } \\
\text { candidato será submetido a } \\
\text { cinco questões sobre este } \\
\text { assunto durante sua } \\
\text { apresentação. }\end{array}$ & Ordinal & $\begin{array}{c}\text { Adimen } \\
\text { sional }\end{array}$ \\
\hline & $\begin{array}{l}\text { Conhecimento } \\
\text { na área da } \\
\text { disciplina }\end{array}$ & Construído & $\begin{array}{l}\text { Conhecimento específico } \\
\text { da disciplina que irá } \\
\text { ministrar. O candidato será } \\
\text { submetido a dez questões } \\
\text { sobre este assunto durante } \\
\text { sua apresentação. }\end{array}$ & Ordinal & $\begin{array}{c}\text { Adimen } \\
\text { sional }\end{array}$ \\
\hline
\end{tabular}

\subsection{VALORAÇÃO DOS ATRIBUTOS CONSTRUÍDOS}

Os atributos construídos apresentados são de natureza qualitativa, com cinco níveis de impacto na opção por uma das quatro alternativas existentes, sendo que serão ordenados preferencialmente, de acordo com o julgamento dos decisores (Quadro 4).

Quadro 4: Descrição dos níveis de impacto dos atributos

\begin{tabular}{|c|c|c|}
\hline Níveis de Impacto & Níveis de Referência & Descrição \\
\hline$N_{5}$ & Muito bom & Muito Alta \\
\hline$N_{4}$ & & Alta \\
\hline$N_{3}$ & Bom & Média \\
\hline$N_{2}$ & & Baixa \\
\hline$N_{1}$ & Neutro & Muito Baixa \\
\hline
\end{tabular}

A função de valor foi obtida empregando-se o método da Pontuação Direta (Direct Rating). Conforme sugerido em Ensslin et al. (2001), ao pior nível admissível $\left(\mathrm{N}_{1}-\mathrm{a}\right.$ alternativa contribui de forma muito baixa para o atingimento do objetivo do atributo analisado) foi associado o valor zero e ao melhor nível viável $\left(\mathrm{N}_{5}\right.$ - a contribuição da alternativa para o atingimento do objetivo é muito alta) foi associado o valor 100 .

\subsection{AVALIAÇÃO DAS ALTERNATIVAS}

Após a abertura do edital para a contratação do docente para atuar nos cursos de Graduação e Pós-Graduação, foram analisadas quatro inscrições e destas somente três foram consideradas, pois atendiam integralmente os pré-requisitos estabelecidos no edital.

Para manter a privacidade dos inscritos, trataremos aqui os inscritos com a terminologia Docente candidato, de forma a identificarmos Docente Candidato 1, Docente Candidato 2 e Docente Candidato 3. Para poder avaliar os quatro candidatos, os decisores analisaram as qualificações de cada um deles, contabilizando a produção científica, orientações, tempo de atuação acadêmica e profissional, formação acadêmica, nível das instituições em que atuaram. Para isto, foi realizada uma reunião com a dupla de Coordenadores que, em posse de suas anotações sobre os dados existentes de 
cada candidato, foram realizando as pontuações de forma consensual. Ressalta-se aqui que, a percepção de valor de cada Candidato (alternativa) aos critérios existentes era muito semelhante, de forma que esta etapa foi realizada sem grandes divergências nas preferências apresentadas.

$\mathrm{Na}$ sequência, foram definidas as taxas de substituição do modelo multicritério, de forma a permitir uma posterior agregação de todas as dimensões de avaliação. Também denominadas tradeoffs ou constantes de escala, as taxas de substituição são medidas que expressam "a perda de performance que uma ação potencial deve sofrer em um critério para compensar o ganho de desempenho em outro" (ENSSLIN et al., 2001, p. 218). Popularmente são conhecidas como pesos.

O método utilizado para determinar as taxas de substituição foi o Swing Weights, baseado no conceito de compensação. Seguindo o passo a passo descrito em Ensslin et al. (2001) foi criada uma ação fictícia, com nível Neutro em todos os critérios, e então foi oferecida aos decisores a oportunidade de melhorar o desempenho desta ação, de Neutro para Bom, em apenas um dos critérios. Ao critério escolhido foi atribuído um salto no valor de 100 . O mesmo procedimento foi repetido para os demais, na ordem de preferência dos decisores, com o valor do salto avaliado em relação àquele critério que recebeu o valor 100. As taxas de substituição foram obtidas a partir da normalização destes valores.

$\mathrm{Na}$ etapa seguinte de avaliação parcial e global das alternativas, foi utilizado o software V.I.S.A., um programa computacional de apoio à decisão desenvolvido pela SIMUL8 (www.simul8.com). A Figura 2 ilustra a árvore de valor completa produzida no V.I.S.A com os pesos de cada critério e subcritério.

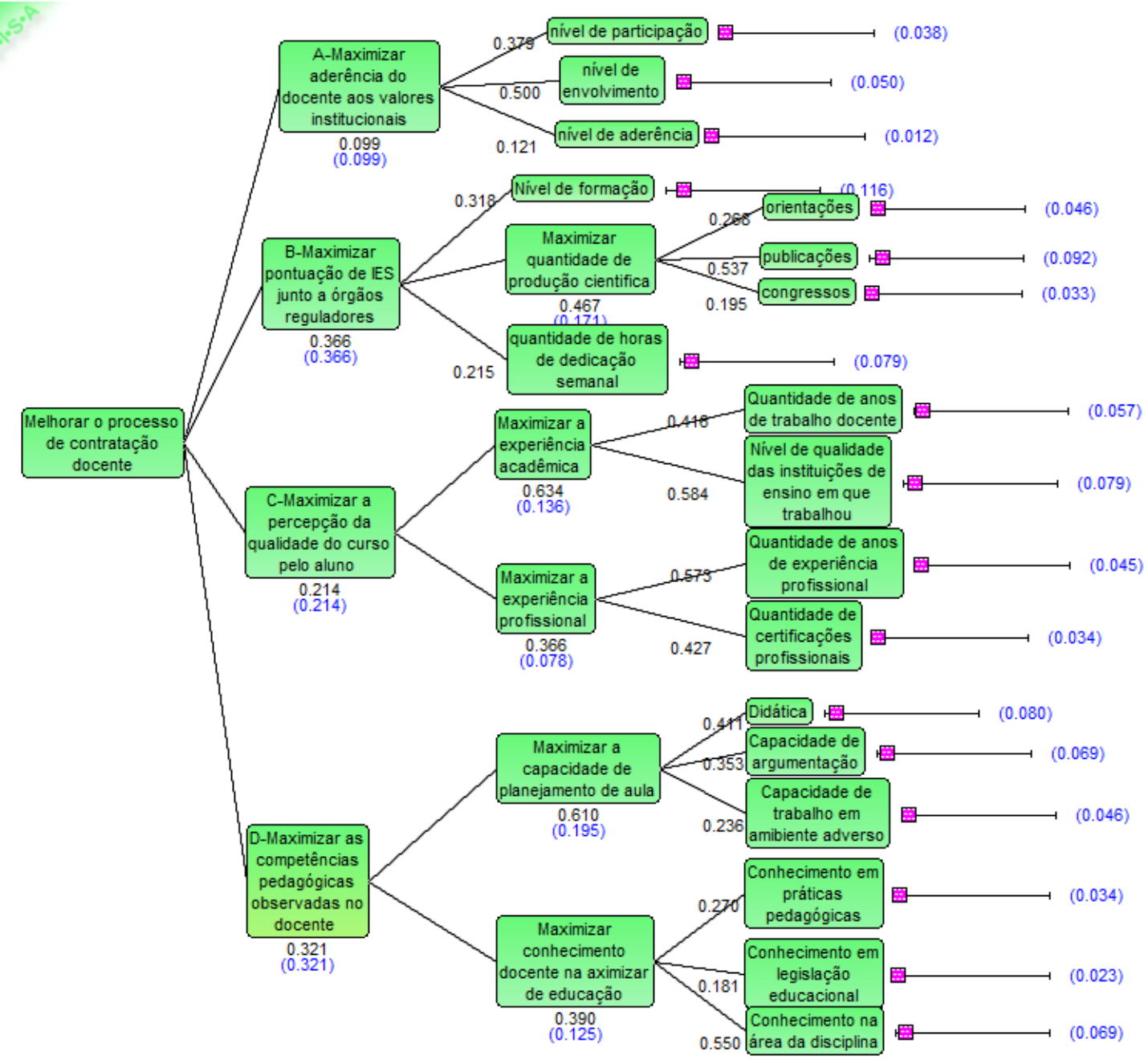

Figura 2: Árvore de valor produzida no V.I.S.A. 


\section{APRESENTAÇÃO DOS RESULTADOS}

Baseado nos resultados obtidos na árvore de valor, na Figura 3 observa-se que o subcritério que mais tem importância na contratação de um docente é o subcritério "B-Maximizar pontuação de IES junto a órgãos reguladores", seguido de "D-Maximizar as competências pedagógicas observadas no docente", contribuindo, respectivamente, com $37 \%$ e $32 \%$ para o alcance do objetivo principal. Nestes subcritérios, encontram-se os critérios nivel de formação, quantidade de publicações e didática que têm os maiores pesos relativos no processo de contratação docente.
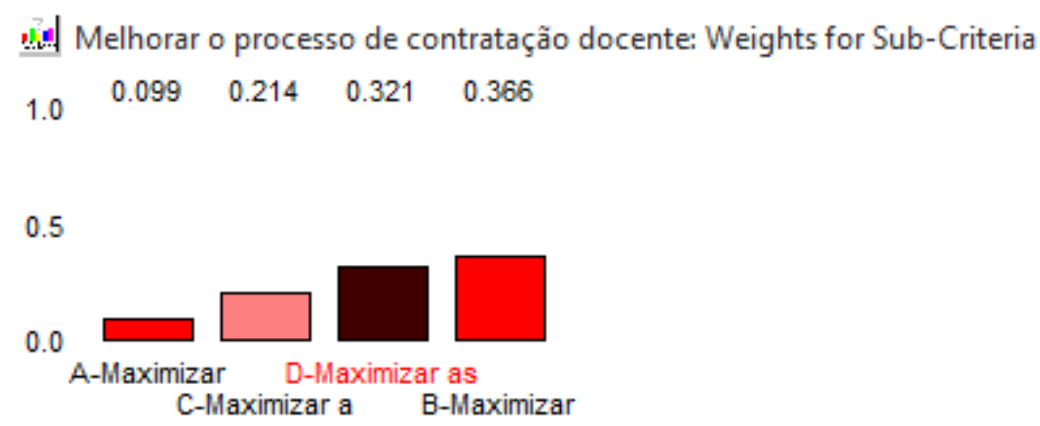

Figura 3: Peso por subcritério

Na figura 4, observa-se a avaliação de cada alternativa por subcritério. É possível observar o desempenho superior nestes dois subcritérios de maior peso pelos candidatos Docente 3 e Docente 4, sendo que o Docente 3 tem o desempate no subcritério "B-Maximizar pontuação de IES junto a órgãos reguladores".

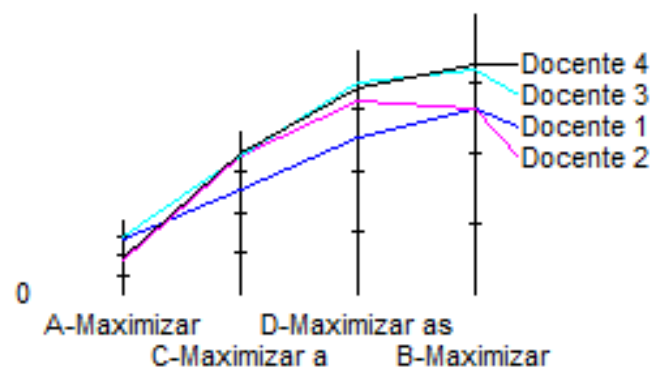

Figura 4: Desempenho do candidato por subcritério

A alternativa Docente 3 é a que mais contribui para o alcance do objetivo principal "Melhorar o processo de contratação docente", pois seleciona o candidato que tem maior pontuação à luz dos critérios definidos e ponderados pelos decisores. A partir da agregação das performances parciais das alternativas, obteve-se o seu desempenho global no modelo multicritério, resultando na pontuação mostrada na Tabela 1, que ilustra o desempenho das alternativas em relação ao objetivo principal.

Tabela 1: Ranking final das alternativas

\begin{tabular}{|c|c|c|}
\hline Alternativa & Avaliação global & Ranking \\
\hline Docente Candidato 3 & 82 & 1 \\
\hline Docente Candidato 4 & 80 & 2 \\
\hline Docente Candidato 2 & 72 & 3 \\
\hline Docente Candidato 1 & 65 & 4 \\
\hline
\end{tabular}


É possível observar que os candidatos Docente 3 e Docente 4 possuem pontuações muito semelhantes, o que torna a seleção de um ou outro, praticamente, indiferente na opinião dos decisores. Os critérios nivel de orientações e nível de publicações são os responsáveis pelo desempate entre os dois candidatos. A pontuação das alternativas, obtida pela aplicação do modelo multicritério, permite quantificar o grau de contribuição de cada ação em potencial para o objetivo fundamental dos decisores.

Por fim, como última etapa da fase de avaliação das alternativas, foi realizada uma análise de sensibilidade. Esta consiste em fazer pequenas mudanças nos valores dos parâmetros do modelo e observar como isto altera o resultado final.

No caso específico deste problema de contratação docente, selecionamos dois critérios para realizar a análise de sensibilidade: didática e nível de orientações. Estes critérios são aqueles que apresentam maior peso no processo de seleção.

Pelo gráfico apresentado na Figura 5 (a) e (b), embora se tenha alterado o valor da avaliação em $10 \%$ na pontuação do candidato Docente 3 , não houve inversão na preferência de contratação do docente.

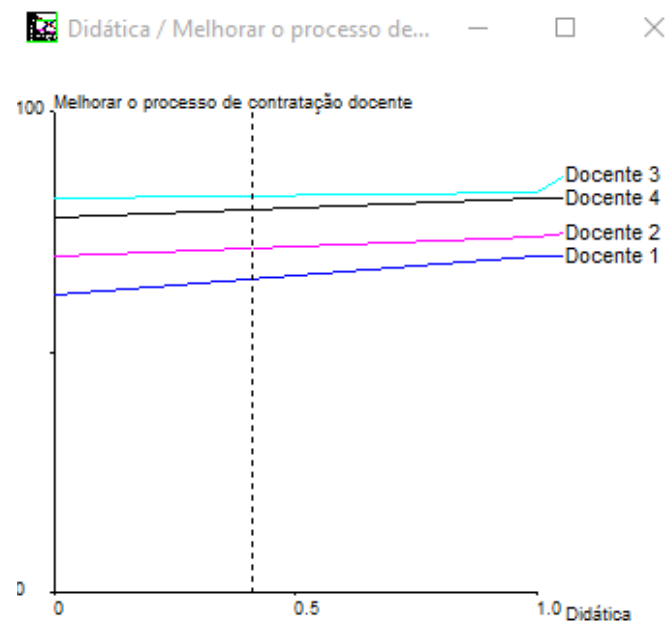

(a)

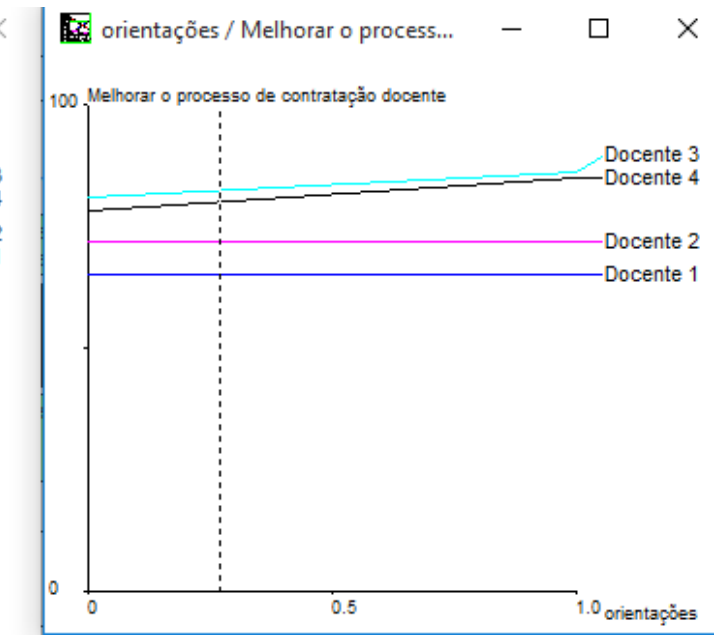

(b)

Figura 5: Desempenho de cada candidato por critério

\section{CONSIDERAÇÕES FINAIS}

Este artigo teve como objetivo apresentar uma sistemática que auxilie os coordenadores do curso de Direito no processo de contratação de docentes que estejam capacitados a ministrar aulas a nível e Graduação e Pós-Graduação Stricto Sensu, de forma que o resultado maximize a pontuação da IES junto a órgãos reguladores e as competências pedagógicas do docente selecionado, que constituem objetivos de grande valor para os dois decisores deste processo.

Para levantamento das informações e elucidação sobre os conceitos e objetivos relacionados ao processo de contratação docente, utilizou-se o método VFT que se mostrou útil na definição dos objetivos fundamentais e meios por ser focado nos valores institucionais. A partir dele foi possível construir o modelo de valor multiatributo e avaliar, de acordo com as preferências dos decisores, o desempenho de cada docente frente aos objetivos da IES de forma a aumentar a assertividade no processo de contratação docente, evitando demissões, reclamações, desgaste nos relacionamentos interpessoais e redução de gastos com processos trabalhistas.

Desta forma, a identificação de critérios que atendam aos valores institucionais e aos valores dos decisores contribui para o aumento da probabilidade de sucesso na contratação de docentes para a IES. 


\section{REFERÊNCIAS BIBLIOGRÁFICAS}

STRADIOTTO SIQUEIRA, Elisabete et al. Seleção de Docentes em Universidades Federais: uma análise dos regulamentos. Ensaio: Avaliação e Políticas Públicas em Educação, v. 20, n. 77 , 2012.

MICHAELS, Ed; HANDFIELD-JONES, Helen; AXELROD, Beth. A Guerra pelo Talento. Rio de Janeiro: Editora Campus, 2002

PESSANO, Carolina Schaan; STOBÄUS, Claus Dieter. Seleção de professores em instituições de ensino superior: colaborando com o estado do conhecimento (Capes 20112012). Educação Por Escrito, 2016.

MARCONI, M. A.; LAKATOS, E.M. Fundamentos de Metodologia Científica. São Paulo: Atlas, 2005.

ENSSLIN, Leonardo; NETO, Gilberto Montibeller; NORONHA, Sandro MacDonald. Apoio à decisão: metodologias para estruturação de problemas e avaliação multicritério de alternativas. Insular, 2001.

RYU, Jae H. et al. Sustainable water resources management in a conflict resolution framework. JAWRA Journal of the American Water Resources Association, v. 45, n. 2, p. 485-499, 2009.

MONTIBELLER, Gilberto; FRANCO, L. Alberto. Raising the bar: strategic multi-criteria decision analysis. Journal of the Operational Research Society, v. 62, n. 5, p. 855-867, 2011.

KEENEY, Ralph L.; RAIFFA, Howard. Decisions with multiple objectives: preferences and value trade-offs. Cambridge university press, 1993.

KEENEY, Ralph L. Value-focused thinking: Identifying decision opportunities and creating alternatives. European Journal of operational research, v. 92, n. 3, p. 537-549, 1996.

KEENEY, Ralph L. Developing objectives and attributes. Advances in decision analysis: From foundations to applications, p. 104-128, 2007. 